DOI: 10.12731/2070-7568-2021-10-3-41-55

УДК 330

\title{
АНАЛИЗ ВЛИЯНИЯ ПАНДЕМИИ НА ДЕЯТЕЛЬНОСТЬ АВИАКОМПАНИЙ НА ПРИМЕРЕ ГРУППЫ КОМПАНИЙ «АЭРОФЛОТ»
}

\author{
Чувашлова М.В., Терехина С.Э., Эпикурова М.Ю.
}

В ходе своего сущуествования каждая компания сталкивается с различными видами рисков, осложняющих ее деятельность. Как показал 2020 год, одним из достаточно опасных рисков можно считать эпидемиологический риск. Ведь, нет ни одной отрасли, которая бы не пострадала из-за введённых мер борьбы с распространением COVID-19. Но едва ли не самый сильный удар пандемия нанесла по деятельности авиакомпаний. Карантин, запрет на международные перевозки пассажсиров оставили авиакомпании без основного источника заработка, заставив их заморозить деятельность и жить на откладываемые годами резервы, чтобы не обанкротиться.

В статье рассмотрено влияние пандемии на сферу авиаперевозок. Выявлены проблемы, с которыми столкнулась сфера авиаперевозок, представлены результаты воздействия данных проблем на операционные и финансовые показатели авиакомпаний, на примере ПАО «Аэрофлот». Также рассмотрены меры принятые ПАО «Аэрофлот», с иелью преодоления негативных последствий пандемии.

Цель исследования. Целью данной статьи является анализ развития авиакомпаний в условиях сложной эпидемиологической ситуации в мире. Анализ динамики показателей деятельности авиакомпаний во время пандемии COVID-19, исследование способов преодоления негативных последствий коронавируса в деятельности авиакомпаний.

Материалы и методы исследования. Методология исследования основывалась на использовании комплексного подхода и формальной логики. На разных этапах исследования, а также в за- 
висимости от характера разрабатываемых задач использовались различные современные методы исследования, в том числе системный анализ и синтез, финансово-экономический анализ, сравнение, вертикальнылй, горизонтальный анализ и т.д.

Результаты. В статье на основе анализа данных бухгалтерской отчетности и операциинных показателей ПАО «Аэрофлот»» проведена оченка изменений, происходящчих в сфере авиаперевозок. Определено влияние распространения коронавируса на деятельность авиакомпаний: выявлены проблемы, с которыми столкнулась сфера авиаперевозок. Вместе с тем, автором определены возможные пути решения, которые могут улучиить ситуацию во время пандемии.

Ключевые слова: пандемия; экономический кризис; авиаперевозки; ПАО «Аэрофлот»; бухгалтерская отчетность

\section{ANALYSIS OF THE IMPACT OF THE PANDEMIC ON THE BUSINESS OF AIRLINES}

\section{Chuvashlova M.V., Terekhina S.E., Epikurova M.U.}

Every day each company faces various types of risks that complicate its activity. Previous year (2020) showed us, that an epidemiological risk is one of the most dangerous risks for business. The coronavirus pandemic has caused enormous damage to different businesses. But the most influence COVID-19 had on airlines. The first decisions that governments of the countries made in connection with the pandemic were to close the passenger flights between the countries. The quarantine and the ban on international passenger transportation have left airlines without income, forcing them to freeze their activities and live on reserves, in order not to go bankrupt.

In this article the author analyzes the impact of the pandemic on the business of airlines. The author examines problems, which airlines faced during the pandemic and explores the impact of these problems on the operational and financial performance of airlines, with the help 
of financial report of Aeroflot. The measures taken by Aeroflot to overcome the negative consequences of the pandemic were also considered.

The purpose. The purpose of this article is to analyze the activity of airlines in a difficult epidemiological situation in the world. The specific objectives of the article are to highlight the impact of the COVID-19 pandemic on the activity of the airline industry and to explore the ways, which can help to overcome the negative consequences of the coronavirus.

Methodology. The research methodology was based on the use of an integrated approach and formal logic. At different stages of the study were used various modern research methods, including system analysis and synthesis, financial and economic analysis, comparison, vertical, horizontal analysis, etc.

Results. In this article the changes taking place in the field of air transportation were assessed with the help of accounting data and operational indicators of Aeroflot. The impact of the spread of coronavirus on the activities of airlines has been determined. As a result of the study, the problems faced by the air transportation industry were identified. At the same time, the author identified possible solutions that can improve the situation during a pandemic.

Keywords: pandemic; economic crisis; air transportation; Aeroflot; accounting statements

COVID-19-заболевание, вызванное специфическим вирусом (SARS-CoV-2) и обозначенное в прессе как «коронавирус» [12]. Пандемия новой коронавирусной инфекции COVID-19 началась в городе Ухане в центральной китайской провинции Хубэй в 2019 году и распространилась на территории более чем 200 стран Европы, Азии, США и Африки, поставив под угрозу существование мировой экономики, вызвав ее стагнацию [3].

Bспышка Covid-19 вызвала шоки как спроса, так и предложения, отражающиеся на мировой экономике. От пандемии коронавируса пострадало множество компаний [15]. Ведь, чтобы сдержать экспоненциальное распространение вируса, страны мира принимали 
такие меры, как изоляция, закрытие границ, введение карантина, ограничение поездок [11]. Понятия «карантин», «самоизоляция» и «социальная дистанция» вошли в повседневный лексикон людей, проживающих в различных странах, регионах [14].

Ввиду этого в 2020 г. индустрия туризма столкнулась с серьезным вызовом в своем развитии [5]. Все субъекты сервисного обслуживания, задействованные в данной сфере, понесли убытки в результате сложившейся ситуации: туристические операторы и агентства, гостиницы, санатории, дома отдыха и пансионаты, экскурсоводы, сфера авиаперевозок [7] .

Согласно исследованиям Всемирного совета путешествий и туризма (WTTC), до пандемии на долю туристической отрасли и сферы пассажироперевозок приходилось 10,6\% всех рабочих мест (334 миллиона) и 10,4\% мирового ВВП (9,2 триллиона долларов США) [1]. Но в результате пандемии сектор путешествий и туризма потерял почти 4,5 трлн долларов США, достигнув 4,7 трлн долларов США в 2020 году, вклад в ВВП снизился на 49,1\% по сравнению с 2019годом [16]. В 2020 году было потеряно 62 миллиона рабочих мест, произошло падение на $18,5 \%$, в результате чего во всем мире в данной сфере было занято всего 272 миллиона человек по сравнению с 334 миллионами в 2019 году [13].

Резкое сокращение спроса на туристические услуги, введение жестких санитарных ограничений негативно повлияло на динамику показателей деятельности авиакомпаний [10]. Еще до того, как COVID-19 был объявлен международной чрезвычайной ситуацией, в городе Ухань, первоначальном эпицентре вируса, затем и в других регионах Китая был объявлен карантин [17]. В результате границы страны были закрыты для гражданской авиации. Следующей страной, предпринявшей подобные меры, стала Италия, из-за скорости распространения вируса. Со временем карантин был объявлен практически по всему миру, а это значит, что большая часть мирового населения, были вынуждены изменить свой социальный и экономический образ жизни, а отрасль гражданской авиации терпела убытки из-за запрета международного передвижения населения [2]. 
По расчетам Международной организации гражданской авиации (ICAO),в 2020 году мировой объем пассажирских перевозок резко сократился приблизительно на $60 \%$, что эквивалентно уменьшению числа пассажиров примерно на 2,7 млрд человек по сравнению с 2019 годом. Согласно оценкам, резкое снижение объема перевозок приведет к падению валовых эксплуатационных доходов авиакомпаний на 370 млрд долл [6]. США, а потери в доходах аэропортов и поставщиков аэронавигационного обслуживания (ПАНО) достигнут 115 и 13 млрд долл. США соответственно. Краткосрочные прогнозы показывают, что отрасли придется сталкиваться со слабым спросом на перевозки в течение длительного времени.

При этом в качестве мер поддержки авиаотрасли Международная организация гражданской авиации (ICAO) назвала следующие меры:

1. Контроль за расходами и управление ими

2. Контрактные переговоры с арендодателями, поставщиками и/или снабженцами

3. Финансирование за счет займов и реструктуризация долга

4. Финансирование за счет акционерного капитала

5. Рациональное использование маршрутов и оптимизация состава самолетного парка

6. Общее уменьшение налоговой нагрузки

7. Государственные займы и гарантии по займам

8. Долевое участие государства в акционерном капитале и т.д. [6].

Рассмотрим на примере ПАО «Аэрофлот» как данная авиакомпания справлялась с влиянием пандемии, какие финансовые и операционные результаты компания показала в 2020 г.

Группа «Аэрофлот» - современный авиационный холдинг, крупнейший авиаперевозчик России, входит топ-20 авиаперевозчиков мира по пассажиропотоку. Головной компанией Группы является ПАО «Аэрофлот». В состав Группы «Аэрофлот» входят сетевые авиакомпании «Аэрофлот», «Россия», «Аврора», а также лоукостер «Победа». Мультибрендовое предложение позволяет максимально охватить все основные сегменты рынка на внутренних и международных направлениях. Группа «Аэрофлот» стремится к лидерству 
среди глобальных перевозчиков. Одно из ключевых преимуществ Группы «Аэрофлот» - современный парк воздушных судов. Парк авиакомпании «Аэрофлот» является одним из самых молодых в мире: средний возраст самолетов составляет пять лет (по Группе семь лет). По состоянию на конец 2020 года парк Группы «Аэрофлот» насчитывал 364 воздушных судна, 241 из которых эксплуатировались авиакомпанией «Аэрофлот» [8].

В 2019 году сеть маршрутов Группы «Аэрофлот» охватывала более 340 регулярных направлений в 57 стран мира. В 2020 количество маршрутов было сокращено, ввиду ограничений, вызванных коронавирусной инфекцией.

Начиная с 1 квартала 2020 года, Группа проводит оптимизацию доступных емкостей, сопоставляя их со спросом и запланированным расписанием полетов, однако сильнейшее снижение спроса повлияло на показатели загрузки и эффективности использования парка ВС:

- За 12 месяцев 2020 г. Группа перевезла 30,2 млн пассажиров, что на 50,3\% ниже результата аналогичного периода 2019 года [8];

- Процент занятости пассажирских кресел по Группе снизился на 8,3 п.п. по сравнению с аналогичным периодом прошлого года и составил 73,6\%;

- Пассажирооборот Группы снизился на 51,6\% по сравнению с аналогичным периодом прошлого года, данные отражены в таблице 1 .

Руководством Группы был принят ряд решений, включая, среди прочего, переориентацию воздушных судов под выполнение грузовых рейсов, сокращение затрат, проведение переговоров с лизингодателями об отсрочке лизинговых платежей, выявление дополнительных возможностей повышения ликвидности и откладывание ряда запланированных внутренних проектов для выполнения текущих обязательств [9]. Важно отметить, что ПАО «Аэрофлот» оказалась одной из самых лояльных авиакомпаний в кризисной ситуации по отношению к пассажирам. В самый пик пандемии значительному количеству пассажиров, чьи рейсы были отменены, данная ави- 
акомпания предложила изменить даты путешествия с сохранением маршрута, но главное, что можно оформить вынужденный возврат и получить полную стоимость за приобретенный билет по месту его приобретения [4].

Таблииа 1.

Основные показатели деятельности ПАО «Аэрофлот» 2019-2020 гг.

\begin{tabular}{|l|c|c|c|c|c|c|}
\hline & $\begin{array}{c}\text { Чет- } \\
\text { вертый } \\
\text { квартал } \\
2019 \text { г. }\end{array}$ & $\begin{array}{c}\text { Чет- } \\
\text { кертый } \\
2020 \text { г. }\end{array}$ & $\begin{array}{c}\text { Измене- } \\
\text { ние }\end{array}$ & 2019 г. & 2020 г. & $\begin{array}{c}\text { Измене- } \\
\text { ние }\end{array}$ \\
\hline $\begin{array}{l}\text { Пассажиропоток, } \\
\text { тыс. чел }\end{array}$ & 13990 & 7100 & $(49,2 \%)$ & 60719 & 30157 & $(50,3 \%)$ \\
\hline $\begin{array}{l}\text { Международные } \\
\text { линии }\end{array}$ & 6161 & 799 & $(87,0 \%)$ & 27118 & 5984 & $(77,9 \%)$ \\
\hline Внутренние линии & 7830 & 6301 & $(19,5 \%)$ & 33601 & 24172 & $(28,1 \%)$ \\
\hline $\begin{array}{l}\text { Пассажжрооборот, } \\
\text { млн пкм }\end{array}$ & 35985 & 14282 & $(60,3 \%)$ & 156253 & 68014 & $(56,5 \%)$ \\
\hline $\begin{array}{l}\text { Международные } \\
\text { линии }\end{array}$ & 21191 & 2520 & $(88,1 \%)$ & 91401 & 21150 & $(76,9 \%)$ \\
\hline Внутренние линии & 14793 & 11762 & $(20,5 \%)$ & 64852 & 46863 & $(27,7 \%)$ \\
\hline $\begin{array}{l}\text { Предельный пасса- } \\
\text { жирооборот, млн. } \\
\text { ккм }\end{array}$ & 45476 & 19140 & $(57,9 \%)$ & 190856 & 92402 & $(51,6 \%)$ \\
\hline $\begin{array}{l}\text { Международные } \\
\text { линии }\end{array}$ & 27433 & 3701 & $(86,5 \%)$ & 113766 & 30039 & $(73,6 \%)$ \\
\hline Внутренние линии & 18042 & 15438 & $(14,4 \%)$ & 77089 & 62363 & $(19,1 \%)$ \\
\hline Занятость кресел, \% & $79,1 \%$ & $74,6 \%$ & $(4,5$ п.п.) & $81,9 \%$ & $73,6 \%$ & $(8,3$ п.п.) \\
\hline $\begin{array}{l}\text { Международные } \\
\text { линии }\end{array}$ & $77,2 \%$ & $68,1 \%$ & $(9,2$ п.п.) & $80,3 \%$ & $70,4 \%$ & $(9,9$ п.п.) \\
\hline Внутренние линии & $82,0 \%$ & $76,2 \%$ & $(5,8$ п.П.) & $84,1 \%$ & $75,1 \%$ & $(9,0$ п.п.) \\
\hline
\end{tabular}

Источник: ПАО «Аэрофлот» [8].

В ходе исследования был проведен анализ бухгалтерской отчетности ПАО «Аэрофлот». В результате было установлено, что оборотные активы ПАО «Аэрофлот» в 2020г. выросли на 39\%, в основном за счет роста денежных средств и их эквивалентов. Увеличение суммы денежных средств и их эквивалентов в 2020 году обусловлено накоплением временно свободных средств на депозитных счетах для последующего финансирования операционной деятельности. 
Внеоборотные активы компании в 2020 году также показали рост, на $31 \%$, в основном за счет роста отложенных налоговых активов. Помимо этого, увеличились и обязательства организации, долгосрочные на $718 \%$, краткосрочные на $17 \%$, за счет роста кредиторской задолженности (обязательств по аренде и т.д.) на 201\% и краткосрочных и долгосрочных заемных средств [9].

Группа арендует воздушные суда и авиационные двигатели, а также прочие объекты (недвижимость, транспортные средства и пр.) по соглашениям аренды с третьими сторонами и связанными сторонами. После введения ограничений на полеты, вызванные COVID-19, Группа приостановила платежи в сторону лизингодателей и инициировала переговоры об отсрочке арендных платежей. Группой были подписаны дополнительные соглашения, предусматривающие отсутствие штрафных санкций и предоставление отсрочки по лизинговым платежам по большей части договоров. Данные изменения условий учитываются как модификация договоров аренды. Общая сумма денежных платежей по аренде за 12 месяцев 2020 г. 88 947млн. руб. и 12 месяцев 2019 г. 133363 млн. руб.

Также для преодоления негативных последствий распространения коронавирусной инфекции была произведена реструктуризация краткосрочной задолженности по кредитам в долгосрочную, привлечено долгосрочное заемное финансирование, что обуславливает рост долгосрочных кредитов и займов.

Значительное изменение испытал собственный капитал компании. Капитал организации сократился на 23\%, несмотря на формирование добавочного и увеличение уставного капиталов. В 2020 году ПАО «Аэрофлот» осуществило дополнительный выпуск ценных бумаг, количество размещенных ценных бумаг составило 1333 919149 штук, номинальной стоимостью 1 рубль. Фактическая цена размещения ценных бумаг составила 60 рублей за каждую дополнительно размещаемую акцию. За счет продажи акций по стоимости, превышающей номинальную, был сформирован добавочный капитал компании [9]. 
На уменьшения капитала ПАО «Аэрофлот» в значительной мере повлияло увеличение убытка и эффект от хеджирования выручки валютными обязательствами.

Таблицуа 2.

Горизонтальный анализ бухгалтерской отчетности ПАО «Аэрофлот» за 2019-2020 гг., млн. руб.

\begin{tabular}{|l|c|c|c|c|c|c|}
\hline \multicolumn{1}{|c|}{ Наименование } & 31.12 .19 & 31.12 .20 & $\begin{array}{c}\text { Абс. } \\
\text { откл. }\end{array}$ & $\begin{array}{c}\text { Доля } \\
\text { откл. }\end{array}$ & $\begin{array}{c}\text { Доля } \\
\text { оанс } \\
\text { ланс } \\
2019, \\
\%\end{array}$ & $\begin{array}{c}\text { в ба- } \\
\text { лансе } \\
\%\end{array}$ \\
\hline Внеоборотные активы & 74307 & 97542 & 23234 & 31,26874 & 37,35 & 35,99 \\
\hline Оборотные активы & 124624 & 173492 & 48868 & 39,21255 & 62,65 & 64,01 \\
\hline Капитал и резервы & 69726 & 53276 & -16449 & $-23,59189$ & 35,05 & 19,66 \\
\hline $\begin{array}{l}\text { Долгосрочные } \\
\text { обязательства }\end{array}$ & 9409 & 76974 & 67565 & 718,0789 & 4,73 & 28,40 \\
\hline $\begin{array}{l}\text { Краткосрочные } \\
\text { обязательства }\end{array}$ & 119796 & 140784 & 20988 & 17,51980 & 60,22 & 51,94 \\
\hline Баланс & 198931 & 271035 & 72103 & 36,24529 & & \\
\hline
\end{tabular}

Источник: составлено и рассчитано автором на основе данных ПАО «Аэрофлот» [9].

Что касается выручки, то по итогам 2020 г. выручка Группы снизилась на 58,4\% по сравнению с прошлым годом и составила 229,7млрд руб. Чистый убыток за 2020 г. составил 96.5 млрд руб. Себестоимость продаж за 12 месяцев 2020 года составила 331734 млн руб., что на 38,9\% ниже показателя за аналогичный период 2019 года. За этот же период снизились расходы на авиационное топливо на $63,8 \%$, на обслуживание в аэропортах - на 54,7\%, а также на питание пассажиров на борту - на $64,8 \%$. В результате оптимизационных мер компании удалось обеспечить совокупное сокращение управленческих и коммерческих расходов на 37,2\% за 2020 год по сравнению с аналогичным периодом 2019 года [9].

Таким образом, из вышеприведенного анализа можно сделать вывод, что в 2020 году Аэрофлот представил достаточно слабые результаты в сравнении с показателями 2019 года. На деятельности группы сказалось влияние пандемии. 
Таблицуа 3.

Ключевые показатели ПАО «Аэрофлот» по российским стандартам бухгалтерского учета, млн. руб.

\begin{tabular}{|l|l|l|l|l|l|l|}
\hline \multicolumn{1}{|c|}{ Показатель } & $\begin{array}{c}\text { Чет- } \\
\text { вертый } \\
\text { квартал } \\
2019 \text { г. }\end{array}$ & $\begin{array}{c}\text { Четвертый } \\
\text { квартал } \\
2020 \text { г. }\end{array}$ & $\begin{array}{c}\text { Изме- } \\
\text { нение }\end{array}$ & 2019 г. & 2020 г. & $\begin{array}{l}\text { Изме- } \\
\text { нение }\end{array}$ \\
\hline Выручка & 129604 & 52816 & $(59,2) \%$ & 551767 & 229766 & $(58,4) \%$ \\
\hline $\begin{array}{l}\text { Себестоимость } \\
\text { продаж }\end{array}$ & 130605 & 78510 & $(39,9) \%$ & 542976 & 331734 & $(38,9) \%$ \\
\hline $\begin{array}{l}\text { Валовая при- } \\
\text { быль/ убыток }\end{array}$ & $(1000)$ & $(25694)$ & н/д & 8791 & $(101968)$ & н/д \\
\hline $\begin{array}{l}\text { Чистая прибыль/ } \\
\text { убыток }\end{array}$ & $(1960)$ & $(30972)$ & н/д & 5287 & $(96527)$ & н/д \\
\hline
\end{tabular}

Источник: ПАО «Аэрофлот» [8].

В результате сильнейшего в истории мировой авиации кризиса, практически полной остановки перевозок на международных направлениях во втором и третьем кварталах, проведения противоэпидемических мер в регионах Российской Федерации, которые привели к существенному давлению на спрос во втором-четвертом кварталах 2020 года, по итогам двенадцати месяцев 2020 года чистый убыток Компании составил 96,5 млрд руб. Оптимизационные инициативы, привлечение дополнительного капитала, меры государственной поддержки позволили обеспечить сохранение квалифицированного персонала и производственной базы ПАО «Аэрофлот», а также обеспечить высокий уровень безопасности полетов в крайне сложной ситуации пандемии. Благодаря оптимизационным инициативам Компании удалось обеспечить дополнительные доходы, в частности от грузовых перевозок, избежать неоптимальных затрат и таким образом частично сдержать негативное влияние кризисных явлений на финансовый результат года.

\section{Список литературь}

1. Всемирный совет по туризму и путешествиям. Отчеты об Экономическом воздействии. URL: https://wttc.org/Research/Economic-Impact

2. Гладкий A. B. Международный туризм vs. COVID-19: тенденции, прогнозы, перспективы // Научный результат. Технологии бизнеса и 
сервиса. 2020. Т. 6, № 4. С. 3-10. https://doi.org/10.18413/2408-93462020-6-4-0-1

3. Дробот Е.В. Мировая экономика в условиях пандемии COVID-19: итоги 2020 года и перспективы восстановления // Экономические отношения. 2020. Том 10, № 4. C. 937-960. https://doi.org/10.18334/ eo.10.4.111375

4. Крюкова Е.M., Шадская И.Г., Соколова А.Г. Пандемия COVID-19: вызовы и точки роста индустрии туризма // Инновации и инвестиции. 2021. № 4. С. 340-342.

5. Логунцова И.В. Индустрия туризма в условиях пандемии коронавируса: вызовы и перспективы // Государственное управление. Электронный вестник. 2020. № 80. С. 50-67.

6. Международная организация гражданской авиации. Руководство по экономическим и финансовым мерам по уменьшению влияния вспышки коронавируса на авиацию. URL: https://www.icao.int/covid/ Pages/default.aspx

7. Оборин M.С. Последствия влияния пандемии COVID-19 на мировой туризм // Сервис в России и за рубежом. 2021. Т. 15, №1. С. 47-58. https://doi.org/10.24412/1995-042X-2021-1-47-58

8. Презентация компании ПАО «Аэрофлот». URL: https://ir.aeroflot.ru/ ru/centr-otchetnosti/prezentacii/

9. Финансовая отчетность ПАО «Аэрофлот». URL: https://ir.aeroflot. $\mathrm{ru} /$ centr-otchetnosti/finansovaja-otchetnost/msfo

10. Щербаков Г.А. Влияние и последствия пандемии covid-19: социально-экономическое измерение // МИР (Модернизация. Инновации. Развитие). 2021. Т. 12, № 1. С. 8-22. https://doi.org/10.18184/20794665.2021.12.1.8-22

11. Ashraf B.N. Economic impact of government interventions during the COVID-19 pandemic: International evidence from financial markets // Journal of Behavioral and Experimental Finance. 2020. Vol. 27. P. 100371. https://doi.org/10.1016/j.jbef.2020.100371

12. Daniel Bachman «The economic impact of COVID-19»// Journal Deloitte Insights. 2020. https://www2.deloitte.com/us/en/insights/ economy/covid-19/economic-impact-covid-19.html 
13. Faus J. This is How Coronavirus Could Affect the Travel and Tourism Industry // World Economic Forum. 2020. https://www.weforum.org/ agenda/2020/03/world-travel-coronavirus-covid19-jobs-pandemic-tourism-aviation/

14. Richard Baldwin and Beatrice Weder di Mauro «Economics in the Time of COVID-19"// Graduate Institute, Geneva and Centre for Economic Policy Research. 2020. 123 p. https:/cepr.org/sites/default/files/news/ COVID-19.pdf

15. Stephanie S. The Global Economic Impacts of COVID-19// Center for Strategic and International Studies. 2020. https://www.csis.org/analysis/ global-economic-impacts-covid-19

16. The World Tourism Organization (UNWTO). Tourism and COVID-19. URL: https://www.unwto.org/tourism-covid-19

17.Zaheer Allam, Chapter 7 - Vital COVID-19 Economic Stimulus Packages Pose a Challenge for Long-Term Environmental Sustainability, Editor(s): Zaheer Allam, Surveying the Covid-19 Pandemic and its Implications, Elsevier, 2020, pp. 97-105. https://doi.org/10.1016/B978-0-12-8243138.00007-3

\section{References}

1. World Travel and Tourism Council. Economic Impact Reports. https:// wttc.org/Research/Economic-Impact

2. Gladkiy A.V. Mezhdunarodnyy turizm vs. COVID-19: tendentsii, prognozy, perspektivy [International tourism vs. COVID-19: Trends, Forecasts, Prospects]. Nauchnyy rezul'tat. Tekhnologii biznesa i servisa. 2020. vol. 6, no. 4, pp. 3-10. https://doi.org/10.18413/2408-9346-20206-4-0-1

3. Drobot E.V. Mirovaya ekonomika v usloviyakh pandemii COVID-19: itogi 2020 goda i perspektivy vosstanovleniya [The global economy in the context of the COVID-19 pandemic: the results of 2020 and the prospects for recovery]. Ekonomicheskie otnosheniya, 2020, vol. 10, no. 4, pp. 937-960. https://doi.org/10.18334/eo.10.4.111375

4. Kryukova E.M., Shadskaya I.G., Sokolova A.G. Pandemiya COVID-19: vyzovy i tochki rosta industrii turizma [Pandemic COVID-19: Challeng- 
es and Growth Points of the Tourism Industry]. Innovatsii $i$ investitsii, 2021, no. 4, pp. 340-342.

5. Loguntsova I.V. Industriya turizma $v$ usloviyakh pandemii koronavirusa: vyzovy i perspektivy [The tourism industry in the context of the coronavirus pandemic: challenges and prospects]. Gosudarstvennoe upravlenie. Elektronnyy vestnik, 2020, no. 80, pp. 50-67.

6. International Civil Aviation Organization. Guidance on economic and financial measures to reduce the impact of the coronavirus outbreak on aviation. https://www.icao.int/covid/Pages/default.aspx

7. Oborin M.S. Posledstviya vliyaniya pandemii COVID-19 na mirovoy turizm [Consequences of the impact of the COVID-19 pandemic on world tourism]. Servis v Rossii i za rubezhom, 2021, vol. 15, no. 1, pp. 47-58. https://doi.org/10.24412/1995-042X-2021-1-47-58

8. Presentation of the company 'Aeroflot'. https://ir.aeroflot.ru/ru/centr-otchetnosti/prezentacii/

9. Financial statements of 'Aeroflot'. https://ir.aeroflot.ru/centr-otchetnosti/ finansovaja-otchetnost/msfo

10. Shcherbakov G.A. Vliyanie i posledstviya pandemii covid-19: sotsial'no-ekonomicheskoe izmerenie [Impact and consequences of the covid-19 pandemic: socio-economic dimension]. MIR (Modernizatsiya. Innovatsii. Razvitie), 2021, vol. 12, no. 1, pp. 8-22. https://doi. org/10.18184/2079-4665.2021.12.1.8-22

11. Ashraf B.N. Economic impact of government interventions during the COVID-19 pandemic: International evidence from financial markets. Journal of Behavioral and Experimental Finance, 2020, vol. 27, 100371. https://doi.org/10.1016/j.jbef.2020.100371

12. Daniel Bachman «The economic impact of COVID-19». Journal Deloitte Insights, 2020. https://www2.deloitte.com/us/en/insights/economy/ covid-19/economic-impact-covid-19.html

13. Faus J. This is How Coronavirus Could Affect the Travel and Tourism Industry. World Economic Forum, 2020. https://www.weforum.org/agenda/2020/03/ world-travel-coronavirus-covid19-jobs-pandemic-tourism-aviation/

14. Richard Baldwin and Beatrice Weder di Mauro «Economics in the Time of COVID-19". Graduate Institute, Geneva and Centre for Economic 
Policy Research, 2020, 123 p. https://cepr.org/sites/default/files/news/ COVID-19.pdf

15. Stephanie S. The Global Economic Impacts of COVID-19. Center for Strategic and International Studies, 2020. https://www.csis.org/analysis/ global-economic-impacts-covid-19

16. The World Tourism Organization (UNWTO). Tourism and COVID-19. https://www.unwto.org/tourism-covid-19

17.Zaheer Allam, Chapter 7 - Vital COVID-19 Economic Stimulus Packages Pose a Challenge for Long-Term Environmental Sustainability, Editor(s): Zaheer Allam, Surveying the Covid-19 Pandemic and its Implications, Elsevier, 2020, pp. 97-105. https://doi.org/10.1016/B978-0-12-8243138.00007-3

\section{ДАННЫЕ ОБ АВТОРАХ}

Чувашлова Марина Владимировна, доктор экономических наук, доцент, декан факультета управления

Ульяновский государственный университет

ул. Льва Толстого, 42, г. Ульяновск, 432970, Российская Федерачия

chuvashlova@mail.ru

Терехина Светлана Эдуардовна, старший преподаватель

Ульяновский институт гражданской авиащии имени главного маршала авиации Б.П.Бугаева ул. Можайского, 8/8, г. Ульяновск, 432071, Российская Федерачия set073@yandex.ru

Эпикурова Мария Юрьевна, магистрант кафедры экономической безопасности, учета и аудита Ульяновский государственный университет ул. Льва Толстого, 42, г. Ульяновск, 432970, Российская Федерачия Masha_epi-97@mail.ru 


\section{DATA ABOUT THE AUTHORS}

Marina V. Chuvashlova, Doctor of Economics, Associate Professor, Dean of the Faculty of Management

Ulyanovsk State University

42, Lev Tolstoy Str., Ulyanovsk, 432970, Russian Federation chuvashlova@mail.ru

Svetlana E. Terekhina, Senior Lecturer

Ulyanovsk Institute of Civil Aviation named after Chief Marshal of Aviation B.P. Bugaev

8/8, Mozhaiskogo Str., Ulyanovsk, 432071, Russian Federation set073@yandex.ru

Maria U. Epikurova, Master Student of the Department of Economic Security, Accounting and Audit

Ulyanovsk State University

42, Lev Tolstoy Str., Ulyanovsk, 432970, Russian Federation Masha_epi-97@mail.ru 